\title{
Degradação da proteína e fibra do caroço de algodão integral (Gossypium hirsutum L.) no rúmen
}

\section{Whole linted cottonseed meal (Gossypium hirsutum L.) protein and fiber degradability in the rumen}

\author{
Deborah Clea RUY'; Carlos de Sousa LUCCI ${ }^{1}$; Laércio MELOTTI ${ }^{1}$; Milton Luiz Moreira \\ $\mathbf{L I M A}^{2}$
}

CORRESPONDENCE TO Cartos de Sousa LucCi Departamento de Criaça do Ruminantes e Alimentaçăo Animal Faculdade de Medlcina Veterinária $\theta$ Zootocitia da USP Av. Duque de Caxias Norte, 225 Caixa Postal 23 13680-000 - Pirassununga - SP Bras/l

\section{RESUMO}

O experimento teve como objetivo avaliar a degradabilidade "in situ" da matéria seca (MS), proteína bruta (PB) e fibra em detergente ácido (FDA) do caroço de algodão integral (CAI) em substituição ao farelo de algodão, empregando-se silagem de sorgo (SS), como único volumoso. Além disso, avaliaram-se as alterações no pH e cinética de fermentação ruminal de 9 bovinos, machos, com fístulas no rúmen. Os tratamentos foram: $A=0 \% \mathrm{CAl}, \mathrm{B}=6,6 \% \mathrm{CAl}$ e C $=15 \%$ CAl; a silagem de sorgo entrou na proporção de $70 \%$ em todos os tratamentos. As rações eram isonitrogenadas, com aproximadamente $12 \%$ de PB na MS. Houve diferença estatística $(p<0,05)$ para a degradação de MS no tempo 48 horas $(A=54,4 \% ; B=54,2 \%$ e $C=58,7 \%)$, de $P B$ às 12 horas $(A=40,3 \% ; B=47,7 \%$; e $C=$ $53,1 \%)$ e de FDA às 48 horas $(A=40,3 \% ; B=41,2 \%$ e $C=45,6 \%)$, ocorrendo maiores taxas de degradação com 0 aumento do nível de CAI na dieta. Os demais parâmetros (volume ruminal, "turn over" do digesto ruminal e pH do conteúdo ruminal) nāo mostraram diferenças significativas entre tratamentos. O emprego crescente de CAI, até 15\% da MS da ração, aumentou a degradação da MS, da PB e da FDA desse produto.

UNITERMOS: Digestibilidade; Ruminantes; Bovinos; Fístula; Caroço de algodão.

\section{INTRODUÇÃO E LITERATURA}

$\mathrm{O}$ farelo de algodāo, segundo o National Research Council $^{16}(1989)$, contém $44,3 \%$ de proteína bruta (PB), 5,0\% de extrato etéreo (EE), 6,6\% de matéria mineral (MM), $12,8 \%$ de fibra bruta (FB), $28,0 \%$ de fibra em detergente neutro (FDN), 20,0\% de fibra em detergente ácido (FDA) e $78,0 \%$ de nutrientes digestíveis totais (NDT) em sua matéria seca (MS), sendo considerado um suplemento protéico.

$\mathrm{O}$ caroço de algodão com linter, de acordo com o National Research Council ${ }^{16}(1989)$, possui $23,0 \%$ de PB, 20,0\% de EE, $44.0 \%$ de FDN, 34,0\% de FDA (sendo deste valor 10,0\% representados pela lignina) e 96,0\% de NDT (Coppock et al. ${ }^{5}$, 1987).

Coppock; Wilks ${ }^{7}$ (1991) afirmaram que o fornecimento de lipídios provenientes de sementes oleaginosas compreende uma liberação lenta da gordura durante o decorrer de todo o dia, devido à regurgitação e remastigação das sementes. Esse fato permitiria ação dos microorganismos ruminais em hidrogenar as ligações duplas dos ácidos graxos insaturados, impedindo o efeito inibidor da gordura sobre a digestibilidade da fibra.

No tocante ao consumo de MS, Anderson et al. ${ }^{1}$ (1979); Smith et $_{\text {al. }}{ }^{21}$ (1981); Sklan et al..$^{20}$ (1992) empregaram CAI em dietas experimentais e não observaram efeitos na ingestão.
Já Coppock et al. ${ }^{6}$ (1985), utilizando de 10 a $30 \%$ de semente de algodão na MS total, encontraram diminuição significativa na ingestão da MS. Mohamed et al. ${ }^{15}$ (1998) verificaram ingestōes menores de MS quando utilizaram 16,5\% de CAI na MS total. Coppock et al..$^{5}$ (1987), em revisāo sobre o assunto, concluíram que o fornecimento de CAI em proporção de até $25 \%$ da MS da dieta não afeta o consumo de alimentos.

Teixeira; Huber $^{24}$ (1989) avaliaram o efeito do tamanho da partícula na incubação de semente do algodāo, empregando-a na forma inteira, quebrada ou moída, e concluíram que, apesar de os desaparecimentos de proteína bruta e matéria seca após 24 horas terem sido maiores com a semente moída, a forma quebrada é a que mais se aproxima do caroço mastigado $(79,8 \%$ e $21,0 \%$ para a forma moída e $51,4 \%$ e $12,7 \%$ para a forma quebrada, respectivamente para proteína bruta e matéria seca). Pena et al. ${ }^{19}$, aquecendo o CAI, obtiveram um aumento no afluxo de aminoácidos para o intestino, em relação ao produto cru.

Tagari et al. ${ }^{23}$ (1986) e Stutts et al. ${ }^{22}$ (1988) observaram maior desaparecimento do caroço cru no rúmen, com 12 horas de incubação. Arieli et al. $^{3}$ (1989) registraram que 0 aquecimento do CAI a temperaturas mais altas que $140^{\circ} \mathrm{C}$ provoca menor chegada de proteína ao duodeno.

Os objetivos do presente trabalho foram avaliar a 
Jegradabilidade da matéria seca, da proteína bruta e da fibra obtida em detergente ácido) do CAI em dietas que substituíam, em níveis crescentes, farelo de algodão por caroço de algodão integral, incluindo avaliação das condições de $\mathrm{pH}$ e sinética ruminal.

\section{MATERIAL E MÉTODO}

O experimento foi desenvolvido na Faculdade de Medicina Veterinária e Zootecnia da Universidade de São Paulo, Campus Administrativo de Pirassununga.

Foram comparados três tratamentos (suplementos protéicos) em raçōes contendo silagem de sorgo como único alimento volumoso: A-100\% de farelo de algodão (FA); B$66 \%$ de farelo. de algodão (FA) e $33 \%$ de caroço de algodão quebrado (CAI); e C-33\% de farelo de algodão (FA) e $66 \%$ de caroço de algodão integral quebrado (CAI). Essas raçōes eram isonitrogenadas e continham $12 \%$ de proteína na MS total; as porcentagens de CAI nas dietas foram: $0 \%, 6,6 \%$ e $15 \%$, respectivamente nos tratamentos $\mathrm{A}, \mathrm{B}$ e $\mathrm{C}$.

A silagem de sorgo foi retirada diariamente do silo no período da manhã e fornecida em duas refeições diárias, bem como os concentrados, às 8 e às 15 horas. $\mathrm{O}$ sal mineral era fornecido pela manhã.

Os animais, em número de 9, mestiços, com peso médio de $400 \mathrm{~kg}$ e dotados de cânulas ruminais, para realização do trabalho de degradabilidade "in situ". O delineamento experimental escolhido foi "change over" $3 \times 3$ com três grupos de animais (Gomes $\left.{ }^{10}, 1985\right)$. O pH ruminal foi analisado em change over, com parcelas subdivididas (Gill $\left.{ }^{8}, 1986\right)$.

A técnica adotada foi a dos sacos de náilon (que continham apenas CAI) suspensos no rúmen, incubados por 1,$5 ; 3,0 ; 6,0$; 12,$0 ; 24,0 ; 48,0$ e 72,0 horas, para determinação das taxas de degradabilidade. No fim dos subperíodos experimentais, cada animal recebia, via cânula, o marcador-polietilenoglicol (PEG 4.000) e Hyden $^{12}$ (1956). Colheu-se líquido ruminal nos tempos $0,1,6,9,12$ e 24 horas para determinação das taxas de passagem da fase líquida e do volume ruminal. $\mathrm{O} \mathrm{pH}$ foi medido nos tempos $-2,0,2,4,6,8,10$ e 12 horas, sendo o tempo zero, de inserção de PEG.

Foram analisadas as degradações "in situ" das fraçōes: MS, PB e FDA do CAI (Orskov et al. ${ }^{17}$, 1980; Mehrez; Orskov ${ }^{14}$, 1977). As análises bromatológicas seguiram a metodologia de Goering; Van Soest ${ }^{9}$ (1970) e do Association Of Official Analytical Chemists ${ }^{4}$ (1984), no caso específico da fibra.

\section{RESULTADOS E DISCUSSÃO}

A Tab. 1 contém a composição bromatológica das matériasprimas utilizadas e das dietas experimentais.

As proporções de FDA, FDN e EE para os concentrados A, $\mathrm{B}$ e $\mathrm{C}$ foram respectivamente de $\mathrm{A}=24,02 ; 38,82$ e 3,$08 ; \mathrm{B}=$ 27,$04 ; 41,36$ e 5,$66 ; \mathrm{C}=29,93 ; 44,78$ e 5,68 .

Os teores de extrato nas três dietas foram influenciados diretamente pelos níveis inferiores de graxa apresentados pelo CAI utilizado no experimento, de $14,4 \%$. Este foi um pouco superior ao valor de $14,1 \%$ encontrado por Karalazos et al. ${ }^{13}$ (1992), porém inferior ao de $20,0 \%$ citado pelo National Research Council ${ }^{16}$ (1989). O teor de lipídios nas três dietas, contudo, manteve-se ainda elevado devido ao teor de EE encontrado na silagem de sorgo, que apresentou valores acima dos normais. A quantidade máxima de lipídios presente no tratamento $\mathrm{C}$ ficou um pouco superior ao limite de $6 \%$, acima do qual a gordura poderia passar a interferir na digestibilidade da fração fibrosa (Palmquist; Jenkins ${ }^{18}$, 1980).

A degradação da MS analisada nos tempos 12, 24, 48 e 72 horas de incubação; a da PB nas 12, 24 e 48h; e da FDA nas 24h, $48 \mathrm{~h}$ e $72 \mathrm{~h}$ podem ser visualizadas na Tab. 2.

Para a MS, não foram encontradas diferenças significativas entre tratamentos nos tempos 12, 24 e 72 horas de incubação. Teixeira; Huber ${ }^{24}$ (1989) encontraram valores inferiores aos do presente trabalho para degradação do CAI quebrado às 12 e 24 horas.

As médias de degradação de MS do CAI no tempo 48 horas

Tabela 1

Composição bromatológica dos alimentos e dietas experimentais, em porcentagens na matéria seca. Pirassununga - SP, 1992.

\begin{tabular}{l|c|c|c|c|c|c|c}
\hline \multicolumn{1}{c|}{ Alimento } & MS & PB & FDA & FDN & EE & MM & CNE(1) \\
\hline Silagem de sorgo & 25,80 & 7,10 & 34,90 & 59,70 & 5,00 & 4,50 & 24,20 \\
Farelo de algodão & 94,60 & 32,60 & 38,10 & 56,30 & 1,20 & 5,20 & 4,70 \\
Caroço de algodão & 93,70 & 25,30 & 40,60 & 53,90 & 14,40 & 9,00 & 4,50 \\
Milho grãos & 94,00 & 11,60 & 2,90 & 12,60 & 5,90 & 1,50 & 68,80 \\
\hline Tratamento A & 46,37 & 12,13 & 31,63 & 53,42 & 4,41 & 4,26 & 26,04 \\
Tratamento B & 46,32 & 12,19 & 32,53 & 54,18 & 5,18 & 4,58 & 24,68 \\
Tratamento C & 46,26 & 12,08 & 33,58 & 55,03 & 6,17 & 4,99 & 23,13 \\
\hline
\end{tabular}

(1) Carboidrato não estrutural, calculado como CNE $=100-(\mathrm{PB}+\mathrm{EE}+\mathrm{MM}+\mathrm{FDN}$ ) (Association of Official Analystical Chemists4, 1984). 
RUY, D.C.; LUCCI, C.S.; MELOTTI, L.; LIMA, M.L.M. Degradação da proteína e fibra do caroço de algodāo integral (Gossypium hirsutum L.) no rúmen. Braz. J. vet. Res. anim. Sci. Säo Paulo, v.33, supl., p.273-277, 1996.

Tabela 2

Degradação da matéria seca (MS), da proteína bruta (PB) e da fibra em em detergente ácido (FDA) do CAl em diferentes tempos de incubação, em porcentagens. Pirassununga - SP, 1992.

\begin{tabular}{|c|c|c|c|c|}
\hline \multirow{2}{*}{$\begin{array}{c}\text { Horário } \\
\text { (h) }\end{array}$} & \multicolumn{3}{|c|}{ Tratamentos } & \multirow{2}{*}{$\begin{array}{l}\mathrm{CV} \\
(\%)\end{array}$} \\
\hline & $A$ & B & $\mathrm{C}$ & \\
\hline $12, \mathrm{MS}$ & 28,46 & 29,00 & 36,05 & $28,72^{\text {ns }}$ \\
\hline $24, \mathrm{MS}$ & 39,96 & 43,18 & 41,38 & $15,94^{n s}$ \\
\hline 48,MS & 54,37 & 54,19 & 58,69 & $\begin{array}{c}7,09 \\
\text { (r. linear) }^{\star}\end{array}$ \\
\hline $72, \mathrm{MS}$ & 64,22 & 63,24 & 64,12 & $7,08^{\mathrm{ns}}$ \\
\hline $12, \mathrm{~PB}$ & 40,88 & 47,71 & 53,31 & $\begin{array}{c}17,12 \\
\text { (r.linear) }^{*}\end{array}$ \\
\hline $24, \mathrm{~PB}$ & 62,79 & 62,06 & 61,89 & 6,60 \\
\hline $48, P B$ & 75,49 & 72,11 & 76,87 & 7,66 \\
\hline $24, F D A$ & 28,70 & 31,08 & 28,18 & $35,78^{\mathrm{ns}}$ \\
\hline 48,FDA & 40,27 & 41,16 & 45,57 & $\begin{array}{c}10,66 \\
\text { (r.linear) }^{\star}\end{array}$ \\
\hline $72, \mathrm{FDA}$ & 52,04 & 50,29 & 49,08 & $12,42^{n s}$ \\
\hline
\end{tabular}

${ }^{*} \mathrm{p}<0,05$

$\mathrm{ns}=$ não significativo

mostraram resposta linear significativa $(p<0,05)$ com aumento de porcentagem degradada, conforme o maior nível de CAI na dieta. Supõe-se que isto poderia ser uma indicação de que as porções fibrosas mais resistentes tiveram uma condição ruminal mais adequada para a digestão do alimento, quando empregadas maiores proporções de CAI na ração. O nível 15\% (tratamento $\mathrm{C}$ ) não apresentou interferência negativa do teor de EE superior a 6\%, contradizendo a observação de Palmquist; Jenkins $^{18}(1980)$.

Os valores obtidos para a degradação da MS do CAI com 72 horas de incubação foram muito próximos aos $63,5 \%$ encontrados às 12 horas de incubação por Tagari et al. ${ }^{23}(1986)$ e não muito inferiores aos valores de 48 horas $(67,5 \%)$ verificados por Arieli et al. ${ }^{3}$ (1989). No entanto, ambos esses AA trabalharam com o CAI moído, o que aumentou a velocidade de desaparecimento do material. Quanto à proteína do CAI, às 12 horas $(\mathrm{p}<0,05)$ a taxa de degradação aumentou

Tabela 3

Degradação efetiva da matéria seca (MS), proteína bruta (PB) e fibra em detergente ácido (FDA) do CAl e respectivos coeficientes de variação (CV), em porcentagens. Pirassununga - SP, 1992.

\begin{tabular}{l|c|c|c|c}
\hline \multirow{2}{*}{ Constituintes } & \multicolumn{3}{|c|}{ Tratamentos } & CV \\
\cline { 2 - 4 } & $\mathrm{A}(\%)$ & $\mathrm{B}(\%)$ & $\mathrm{C}(\%)$ & $(\%)$ \\
\hline MS & 32,02 & 32,74 & 34,10 & 11,36 \\
PB & 48,14 & 46,96 & 49,31 & 17,33 \\
FDA & 19,90 & 21,06 & 20,60 & 29,36 \\
\hline
\end{tabular}

linearmente com o acrécimo de CAI na dieta. O CAI apresenta uma porção de proteína solúvel elevada $(38,3 \%)$, segundo Arieli et al. (1989), bem como uma quantidade de proteína degradável no rúmen superior à do farelo de algodão (Stutts et al. ${ }^{22}, 1988$; Arieli et al. ${ }^{3}$, 1989). Para os tempos se 24 e 48 horas não ocorreram diferenças significativas entre os tratamentos. Os CV observados nesse período de incubação foram considerados aceitáveis. Os valores médios de degradação da PB observados até 48 horas foram inferiores aos da literatura, com taxa média de $47,3 \%$ encontrada às 12 horas de incubação, contrastando com valores próximos a $84 \%$ dos trabalhos de Pena et al. ${ }^{19}$ (1986); Stutts et al. ${ }^{22}$ (1988) e Arieli et al. ${ }^{3}$ (1989) e de $92,7 \%$ segundo Tagari et al. ${ }^{23}$ (1986), para o mesmo horário. Essas diferenças estariam provavelmente ligadas ao fato de o material ter sido moído, nos experimentos mencionados. $\mathrm{O}$ desaparecimento percentual da PB do CAI quebrado observado no presente trabalho foi superior àquele de $21,5 \%$ verificado por Teixeira; Huber ${ }^{24}$ (1989) às 24 horas.

No que tange a fibra, no tempo de 48 horas houve resposta linear $(\mathrm{p}<0,05)$ (semelhante à degradação da MS), com aumento da degradação da FDA nos níveis mais elevados de CAI. Os resultados encontrados neste parâmetro parecem reforçar a possibilidade de a dieta promover ação maior dos microorganismos celulolíticos nas porçōes fibrosas do CAI.

$\mathrm{Na}$ Tab. 3 são mostradas as degradações efetivas da $\mathrm{PB}$, da MS e da FDA, assumindo taxa de passagem de $2 \%$ por hora.

Não ocorreram diferenças significativas entre tratamentos.

As taxas de degradação efetiva de PB mostraram valores médios bem superiores, correspondendo a aproximadamente o triplo da MS e mais do dobro da PB do CAI quebrado encontrados por Teixeira; Huber ${ }^{24}$ (1989) (9,2 e 18,1\%, respectivamente), assumindo a mesma taxa de passagem utilizada neste experimento $(0,02)$. Entretanto a degradação efetiva da MS encontrada neste caso foi bem inferior ao valor de $70,5 \%$ observado por Arieli $^{2}$ (1994), empregando $25 \%$ de CAI na MS da dieta de ovinos e assumindo uma taxa de passagem de $0,05 / \mathrm{h}$.

Os resultados referentes à cinética de rúmen podem ser observados na Tab. 4, onde as variáveis ruminais não foram afetadas significativamente pelo nível de CAI na ração.

Os valores de $\mathrm{pH}$ do fluido ruminal obtidos para os tratamentos estudados não apresentaram diferenças significativas, concordando com os trabalhos de Horner et al. ${ }^{11}$ (1988) e Mohamed et al. ${ }^{15}$ (1988), que empregaram CAI em dietas com bovinos. 
RUY, D.C.; LUCCI, C.S.; MELOTTI, L.; LIMA, M.L.M. Degradação da proteína e fibra do caroço de algodāo integral (Gossypium hirsutum L.) no rumeñ. Braz. J. vet. Res. anim. Sci. São Paulo, v.33, supl., p.273-277, 1996

Tabela 4

Parâmetros da cinética de rúmen de animais ingerindo níveis crescentes de CAl na dieta e respectivos coeficientes de variaçāo (CV). Pirassununga - SP. 1992.

\begin{tabular}{|c|c|c|c|c|}
\hline \multirow[t]{2}{*}{ Parâmetros } & \multicolumn{3}{|c|}{ Tratamentos } & \multirow{2}{*}{$\begin{array}{l}\text { CV } \\
(\%)\end{array}$} \\
\hline & A & $\mathrm{B}$ & $\mathrm{C}$ & \\
\hline Volume ruminal (1) & 72,15 & 70,11 & 70,05 & 17,79 \\
\hline Taxa de renovaçäo (x/dia) & 1,64 & 1,63 & 1,74 & 29,95 \\
\hline Taxa de passagem de líquidos $(\% / h)$ & 6,84 & 6,82 & 7,25 & 27,70 \\
\hline $\mathrm{pH} \mathrm{O}$ horas & 6,81 & 6,86 & 6,85 & 2,84 \\
\hline $\mathrm{pH} 2$ horas & 6,43 & 6,45 & 6,43 & 2,10 \\
\hline $\mathrm{pH} 4$ horas & 6,43 & 6,35 & 6,37 & 2,76 \\
\hline $\mathrm{pH} 6$ horas & 6,26 & 6,26 & 6,21 & 2,51 \\
\hline $\mathrm{pH} 8$ horas & 6,25 & 6,28 & 6,16 & 2,93 \\
\hline $\mathrm{pH} 10$ horas & 6,36 & 6,26 & 6,30 & 3,85 \\
\hline $\mathrm{pH} 12$ horas & 6,44 & 6,30 & 6,40 & 3,37 \\
\hline
\end{tabular}

\section{CONCLUSÕES}

Nas condiçōes do presente experimento, as seguintes conclusōes podem ser colocadas:

1. Com o emprego de maiores proporçōes do caroço de algodāo integral nas rações, as taxas de degradabilidade ruminal da MS, no tempo de 48 horas de incubação, da $\mathrm{PB}$, no tempo de 12 horas de incubação, e da fibra bruta, no tempo de 48 horas de incubação, aumentaram de forma linear $(p<0,05)$.

2. O uso de caroço de algodāo integral, nos níveis de até
$15 \%$ da matéria seca das raçōes, implica taxas de degradabilidade ruminal mais elevadas para o próprio caroço de algodão.

3. Os tratamentos não exerceram influência sobre os volumes líquidos do conteúdo ruminal, sobre as taxas de passagem da fase líquida, sobre as taxas de renovação diária da fase líquida ou sobre os tempos de renovação do conteúdo líquido em horas, nem exerceram influência nos valores de $\mathrm{pH}$ dos conteúdos ruminais.

\section{SUMMARY}

Evaluation of "in situ" degradability of DM, CP and ADF of whole linted cottonseed (WLC) when used up to 15\% of the diet (dry matter basis), replacing cottonseed meal, was the main purpose of this experiment. Sorghum silage (SS) was the only roughage. Ruminal $\mathrm{pH}$ and rumen kinetics were also evaluated. Nine ruminal canulated steers were used in a $3 \times 3$ change-over design to evaluate the following treatments: $A=0 \%$ WLC; $B=6.6 \%$ WLC; and $C=15.0 \%$ WLC. Sorghum silage contributed with $70 \%$ in all three treatments. DM degradability at $48 \mathrm{~h}$ incubation time was statistically different $(p<0.05)(A=54.4 \% ; B=54.2 \%$ and $C=58.7 \%)$, as well as PB degradability at $12 h(A=40.3 \% ; B=47.7 \%$ and $C=53.1 \%)$ and $A D F$ degradability at $48 \mathrm{~h}(A=40.3 \% ; B=41.2 \%$ and $C=45.6 \%)$. Ruminal volume, turn over time and ruminal $\mathrm{pH}$ weren't affected by the experimental diets. Substitution of WLC for cottonseed meal up to $15 \%$ diet increased degradability of DM, CP and ADF of WLC.

UNITERMS: Fistula; Bovidae; Cottonseed; Digestibility; Ruminants.

\section{REFERÊNCIAS BIBLIOGRÁFICAS}

1-ANDERSON, M.I.; ADAMS, D.C.; LAMB, R.C.; WALTERS, J.L. Fceding whole coltonsed to lactalting dairy cows. Journal of Dairy Science, v.62, n, 7 , p. $1098-103,1979$

2-ARIELI. A. Effect of whole coltonseed on energy partitioning and nitrogen halance in sheep. Animal Production, v.58, n. 1, p.103-8, 1994

3-ARIEI.I, A.: BLN-MOSHL: A.: ZAMWEL, S.; TAGARI. H. In situ evaluation of the ruminal and intestinal digestibility of heat-treated coltonseeds. Journal of Dairy Science, v. $72, n .5$, p. $1228-33,1989$
4-ASSOCIATION OF OFFICIAL ANALYTICAL CHEMISTS Official methods of analysis. 14.ed. Washington, AOAC, 1984. $1141 \mathrm{p}$.

5-COPPOCK, C.E.; LANHAM, J.K; HORNER, J.I. A review of the nutritive value and utilization of whole cottonseed, cottonsecd meal and associated by-products hy dairy catıle. Animal Feed Science and Technology, v. 18, n.2, p.89-129, 1987

6-COPPOCK C.E: MOYA, J.R: WEST, J W : NAVE, D.H: LABORE, J M GATES, C.E. Effect of lint on whole coltonseed passalge and digestibility and diet choice on intake of whole coltonseed by holstein cows. Journal of Dairy Science, v. 08, n.5, p. $1198-206,1985$ 
RUY, D.C.; LUCCI, C.S.; MELOTTI, L.; LIMA, M.I..M. Degradação da proteína e fibra do caroço de algodão integral (Gossypium hirsutum L.) no rúmen. Braz. J. vet. Res. anim. Sci. São Paulo, v.33, supl., p.273-277, 1996.

7-COPPOCK, C.E.; WILKS, D.L. Supplemental fat in high-energy rations for lactating cows: cffects on intake, digestion, milk yield and composition. Journal of Animal Science, v.69, n.9, p.3826-37, 1991.

8-GILL, J.L. Design and analysis of experiments - in the animal and medical sciences. Iowa, The lowa State University Press, 1986. v.2, 304p.

9-GOERING, H.K.; VAN SOEST, P.J. Forage fiber analyses: apparatus, reagents, procedures and some applications. Washington, USDA/Agricultural Research Service, 1970. $19 \mathrm{p}$.

10-GOMES, F.P. Curso de estatística experimental. 11.ed. Piracicaba, Nohel/ESALQ, 1985. 430p.

11-HORNER, J.L.; COPPOCK, C.E.; MOYA, J.R.; LABORE, J.M.; LANHAN, J.K. Effects of niacin and whole cottonseed on ruminal fermentation, protein degradahility and nutrient digestihility. Journal of Dairy Science. v. 71 , n.5, p.1239-47, 1988 .

12-HYDEN, S. A turbidometric method for the determination of higher polyethylene glycols in hiological materials. Kungliga I antbrukshogskolans Annaler, v.22, n.1, p.139-45, 1956 .

13-KARALAZOS, A.; DOTAS, D.; BIKOS, J. A note on the apparent digestibility and nutritive value of whole cottonseed given to sheep. Animal Production, v. 55, n. 2, p. $285-7,1992$

14-MEHREZ, A.Z.; ORSKOV, E.R. A study of the artificial fibre bag technique for determining the digestibility of feeds in the rumen. Journal of Agricultural Science, v.88, n.3, p.645-50, 1977.

15-MOHAMED, O.E.; SATTER, L.D.; GRUMMER, R.R.; EHLE, F.R. Influence of dietary cottonseed and soybean on milk production and composition. Journal of Dairy Science, v. 71, n. 10, p.2677-88, 1988.

16-NATIONAL RESEARCH COUNCIL. Nutrient requirements of dairy cattle 6.ed. Washington, National Academy Press, 1989. 158p.

17-ORSKOV, E.R.: HOVELL, F.D.B.; MOULD, F. Uso de la técnica de la bolsa de nylon para la valiación de los alimentos. Producción Animal Tropical, v.5, n. 3, p. $213-33,1980$

18-PALMQUIST, D.L.; JENKINS, T.C. Fat in lactation rations: review. Journal of Dairy Science, v.63, n. 1, p.1-14, 1980.

19-PENA, F.; TAGARI, H.; SATTER, L.D. The effect of heat treatment of whole cottonseed on site and extent of protein digestion in dairy cows. Journal of Animal Science, v.62, n.5, p.1423-33, 1986.

20-SKLAN, D.; ASHKENAZI, R.: BRAUN, A.; DEVORIN, A.; TABORI, K. Fally acids, calcium soaps of fatty acids and cottonseeds fed to high yielding dairy cows. Journal of Dairy Science, v.75, n.9, p.2463-72, 1992.

21-SMITH, N.E.; COLLAR, L.S.; BATH, D.L.; DUNKLEY, W.L.; FRANCKE, A.A. Digestibility and effects of whole cottonseed fed to lactating cows. Journal of Dairy Science, v.64, n.10, p.2209-15, 1981.

22-STUTTS, J.A.; NIPPER, W.A.; ADKINSON, R.W.; CHANDLER, J.E.; ACHACOSO. A.S. Protein solubility, in vilro ammonia concentration, and in situ disappearance of extruded whole cottonseed and other protein sources. Journal of Dairy Science, v.71, n. 12, p.3323-33, 1988.

23-TAGARI, H.; PENA, F.; SATTER, L.D. Protein degradation by rumen microbes of heat-1reated whole cottonsed. Journal of Animal Science, v.62, n.6, p.1732-6. 1986.

24-TFiXEIRA, J.C.: HUBBER, J.T. Determinação da digestibilidade pós-ruminal di proteína de semente de algodāo pela técnica do saco de náilon em vacas leitciras. Revista da Sociedade Brasileira de Zootecnia. Viçosa, v. 18, n.4 p.205-3(15, 1989) 